\title{
Research of Behavior of Migration of Uranium in Soil and Plants when Exposed to Petroleum and Reservoir Waters oil and Gas Fields. Model Experiments
}

\author{
Anastasiya S. Mironova ${ }^{a}$ and Lidia G. Bondareva*a,b \\ ${ }^{a}$ Siberian Federal University \\ 79 Svobodny, Krasnoyarsk, 660041, Russia \\ ${ }^{b} \mathrm{Federal}$ Research Center of Hygiene \\ named after F.F. Erisman of Rospotrebnadzor \\ 2 Semashko Str., Moscow Region, Mytischi, 141014, Russia
}

Received 26.09.2015, received in revised form 19.02.2016, accepted 02.03.2016

There are natural radionuclides in the composition of oil and oil products. As a result of accidents oil fall on the surface of the earth is their filtration into the soil. This leads to the accumulation of radionuclides in the soil. Then natural radionuclides migrate into plants and further along the trophic chains. In this paper, using the model experiment was traced the migration of uranium-238 in the soil-plant system using flower culture - marigold (Tagetes erecta). The soil-plant systems were made pollutants: a) oil; b) associated petroleum water; c) the oil mixture containing uranium salt. Soil extracts were prepared by sequential fractionation method. Out of uranium from the soil was determined in extracts. Ammonium acetate extractor was performed from dried plants. The remaining biomass was subjected to wet digestion. It was determined the uranium content in the plants. The experiment showed that about $96 \%$ of the uranium is associated with the soil components (organic matter, clay minerals) after application, and about $2 \%$ of the uranium extracted from the soil together with moving fractions and accumulated in the plant.

Keywords: uranium-238, soil-plant system, soil extracts, migration, sequential fractionation.

DOI: $10.17516 / 1998-2836-2016-9-1-29-41$.

(C) Siberian Federal University. All rights reserved

* Corresponding author E-mail address: lydiabondareva@gmail.com 


\title{
Исследование особенностей миграции урана \\ в почве и растениях при воздействии нефти \\ и пластовых вод нефтегазопромысла. \\ Модельные эксперименты
}

\author{
А.С. Миронова ${ }^{\mathrm{a}}$, Л.Г. Бондарева ${ }^{\mathrm{a}, \overline{6}}$ \\ ${ }^{a}$ Сибирский федеральный университет \\ Россия, 660041, Красноярск, пр. Свободныий, 79 \\ ${ }^{6}$ ФБУН «Федеральный научный иентр гигиены \\ им. Ф.Ф. Эрисмана» Роспотребнадзора
}

Россия, 141014, Мылищии, Московская область, ул. Семашко, 2

Нефть и нефтепродукты содержат в своем составе естественные радионуклиды. При попадании нефтепродуктов на земную поверхность в результате аварий на нефтегазопромысле происходит их дальнейтая фильтрачия в глубь почвы, что приводит к накоплению в почве радионуклидов. Затем естественные радионуклиды мигрируют в растения и дальше по трофическим цепям. В данной работе посредствоммодельного эксперимента была прослежена миграчия урана-238 в системе «почва - растение» на примере иветочной культуры бархатиы (Tagetes erecta). На почву и растения воздействовали с помощью загрязнителей: а) нефти; б) пластовой (подтоварной) воды; в) смеси нефти с солью урана. Методом последовательного фракционирования были получены почвенные экстракты, в которых определялся выход урана из почвы. Информацию о содержании урана в растениях получили, выполнив ацетат-аммонийную вытяжку из высушенных растений, а после проведя мокрое озоление оставшейся биомассы. Эксперимент показал, что около 96 \% урана связывается с компонентами почвы (органическим веществом, глинистыми минералами) после внесения, а около $2 \%$ урана извлекается из почвы вместе с подвижными фракциями и накапливается в растениях.

Ключевые слова: уран-238, система «почва -растение», почвенные экстракты, миграџия, последовательное фракционирование.

\section{Введение}

Нефть, газ и пластовые воды, контактируя с вмещающими породами, растворяют и содержат в своем составе многие химические вещества, включая природные радионуклиды урана-238, тория-232, калия-40 [1-8], радия-226 [7, 9]. При добыче нефти происходит вынос этих радиоактивных веществ на дневную поверхность, где их количественное содержание может варьироваться от незначительного превышения естественного фона до величин, опасных для здоровья работников промысла и объектов природной среды [7, 10-12].

Основные источники естественных радионуклидов (ЕРН) на территории нефтегазопромысла: технологическое оборудование, факельное хозяйство, нефтяные амбары и шламонакопители, участки нефтерозливов. 
В процессе добычи нефти при подъеме жидкости по стволу скважины происходит выпадение радиоактивных солей в электроцентробежных насосах, насосно-компрессорных трубах и поверхностных резервуарах. Осадки, скопившиеся на технологическом оборудовании скважин, на 90-95 \% состоят из радиоактивного радиобарита $-\mathrm{Ba}(\mathrm{Ra}) \mathrm{SO}_{4}$ [3]. При сжигании природного газа в окружающую среду также поступают радионуклиды, в частности радон $\left({ }^{222} \mathrm{Rn}\right)$. Уровень радиации в зонах факелов по сжиганию неутилизируемых компонентов нефти и газа выше фонового на 43 \%. В результате распада радона образуются долгоживущие радионуклиды: свинец-210, висмут-210 и полоний-210. При попадании даже в небольшом количестве этих радионуклидов вместе с пылью и аэрозолями в легкие человека сильно повышается риск заболевания раком легких $[2,3,11]$. На земную поверхность вместе с нефтью выносятся попутные компоненты: нефтешлам, содержащий углеводороды (тяжелые фракции нефти, асфальтосмолистые вещества, парафины), пластовая вода и минеральная часть, в которой присутствует радиобарит. Обычно такие отходы складируют в шламовых амбарах. В некоторых случаях нефтешлам в амбарах из грунта выжигают, что приводит к выбросам летучих токсикантов и радионуклидов в атмосферу, а следовательно, их воздушный перенос. Кроме того, оставшийся прокаленный песок, содержащий ионы тяжелых металлов и радионуклиды, часто используют для отсыпки дорог и засыпания выемок амбаров. Это способствует интенсивной миграции ЕРН и загрязнению ими территории нефтегазопромысла. Рассолы и нефть, поступающие на локальные площадки почв в результате аварий или при недостаточном контроле процесса добычи, растекаются по поверхности и частично фильтруются в глубь почвенных профилей, что приводит к накоплению радионуклидов в почве, а затем миграции их в растения. ЕРН включаются в обменные процессы организмов, приводя зачастую к их сильной интоксикации, и накапливаются в трофических цепях $[2,12]$.

На уровень накопления радионуклидов в почвах и на интенсивность последующего их включения в химические, экологические и пищевые цепи в значительной степени влияют гранулометрический состав и физико-химико-биологические свойства почв [1, 13-20], а также физико-химические свойства самого радионуклида $[1,15,18,21]$.

Цель данной работы - посредством модельного эксперимента проследить миграцию урана-238 в системе «почва - растение» на примере цветочной культуры бархатец (Tagetes erecta), воздействуя на почву различными загрязнителями.

Уран-238 в почвах находится в форме $\mathrm{UO}_{2}{ }^{2+}$, который образует с органическим веществом почвы хорошо растворимые комплексы, что увеличивает его подвижность в почве и биодоступность для корневой системы растений [21-24].

Данный химический элемент был выбран для наблюдений по следующим причинам:

1) недостаточная изученность особенностей миграции в объектах окружающей среды;

2) слабая радиоактивность, что обеспечивает безопасность эксперимента;

3) потенциальная опасность изотопа урана (U-238), так как в результате его распада образуются сильнорадиоактивные изотопы (Th-234, Th-230, Ra-226 и др.);

4) скрытая опасность - токсические свойства. Находясь вне организма, уран составляет лишь незначительную угрозу из-за своего относительно слабого гамма-излучения (в том случае, если его воздействие не носит длительного характера). При вдыхании или попадании 
внутрь организма механическим путем он, выделяя альфа-частицы, повышает риск заболевания раком легких или костных тканей;

5) доступность химического анализа (ICP-MS) для определения урана в полученных пробax.

\section{Экспериментальная часть}

\section{Объекты исследования}

Почва (серая лесная, средний суглинок, средней кислотности (рН 5,1-5,5)) отобрана вблизи лесного массива и жилых строений кампуса СФУ методом конверта (согласно ГОСТ 17.4.3.0183 и ГОСТ 17.4.4.02-84 [25, 26]). Кларк содержания урана для почвы (по А.П. Виноградову, 1975 и по Н. Bowen, 1966) 1 мг/кг. По данным [27], среднемировые значения содержаний U в почвах лежат между 0,79 и 11 мг/кг.

Бархатец прямостоячий (Tagetes erecta L.) - эффектное цветочное растение, кроме декоративной функции играющее еще и роль «садового лекаря», обеззараживающее почву, в которой растет. Относится к одному из самых распространенных видов летников. Растение в зависимости от вида и сорта высотой от 15-20 до 70-80 см. Корневая система мочковатая. Листья при растирании издают специфический запах, свойственный всему растению. Бархатцы неприхотливы, быстро растут. Все их виды легко размножаются семенами через рассаду. Бархатцы растут и обильно цветут все лето, до первых заморозков, после наступления которых быстро погибают [28]. В работах [29, 30] также было отмечено, что бархатцы (Tagetes erecta L.) являются фиторемедиантом в условиях загрязнения нефтью и нефтешламом [30].

В эксперименте была использована нефть с месторождения Западной Сибири (Томская область). Наличие в нефти урана приурочено к смолисто-асфальтеновой фракции. Содержание урана в различных типах нефтей колеблется в пределах двух порядков: $\mathrm{n} \times 10^{-4}-\mathrm{n} \times 10^{-2} \%$, т.е. до 10-15 мг на 100 г нефти [2]. В эксперименте использовалась также подтоварная вода (попутно-добываемая пластовая вода), которая была извлечена совместно с этой же нефтью, а в дальнейшем отделена от нее с помощью делительной воронки. Известно, что данная вода имеет высокую минерализацию 15-17 г/л и также содержит в себе растворенный уран. По данным [31], среднее содержание урана в накипи (минеральном осадке) подземных вод Томской области 1,9 мг/кг.

\section{Методика эксперимента}

Почва была очищена от крупных фрагментов: остатков растений, камней и других инородных предметов. Пробы почвы массой 300,0 г были помещены в ёмкости (пластиковые стаканы) с дренажной системой. Всего было подготовлено 8 проб.

На первой стадии эксперимента проводили регулярный полив систем обычной (отстоявшейся водопроводной) водой для того, чтобы перевести почву в естественно-влажное состояние и предупредить последующее полное высыхание почвы. Через четыре недели полива в ёмкости с почвой было высажено по три саженца Tagetes erecta L. Через две недели в ёмкости были внесены растворы:

1, 2 - вода (контроль); 
3,4 - 15 мл нефти и 480 мкг урана в виде раствора соли $\left(\mathrm{UO}_{2}\left(\mathrm{NO}_{3}\right)_{2}\right)$;

5,6 - 15 мл нефти;

7,8 - 15 мл пластовой воды.

Ёмкости были закрыты полиэтиленовыми пакетами для создания микроклимата в каждой системе и предотвращения испарения внесенных растворов. Через неделю был осуществлен полив обычной водой, через пять дней после этого ёмкости были разобраны.

Была отдельно собрана почва с корней и высушена при температуре $80{ }^{\circ} \mathrm{C}$ в сушильном шкафу до воздушно-сухого состояния. Остальная почва была перемешана, разделена на две части, одна часть которой была высушена при температуре $80{ }^{\circ} \mathrm{C}$ в сушильном шкафу, другая хранилась в морозильной камере при температуре минус $10^{\circ} \mathrm{C}$ до момента подготовки к анализу.

Растения были разделены на надземную и корневую части и высушены в сушильном шкафу при температуре $80{ }^{\circ} \mathrm{C}$.

Каждая часть растения подверглась ацетат-аммонийной вытяжке. Для этого навеску сухой биомассы (2 г) смешивали с 20 мл $1 \mathrm{M} \mathrm{CH}_{3} \mathrm{COONH}_{4}$ и оставляли на сутки с периодическим перемешиванием. Затем твердую часть отфильтровывали с помощью фильтра «синяя лента» и проводили измерения полученных объемов экстракта. Высохшие на фильтре пробы были растворены методом «мокрого озоления» [32].

Из проб почв были последовательно выделены водорастворимая и обменная формы связанных элементов. Методики выбраны согласно литературным данным [2, 23].

Водорастворимые формы (фракция 1) были получены путем смешивания и встряхивания навески исследуемой почвы (10 г) с 100 мл дистиллированной воды в течение суток при соотношении почва - раствор 1:10.

Обменные формы (фракция 2) были получены путем смешивания и встряхивания навески исследуемой почвы (10 г) с 100 мл ацетатно-аммонийного буферного раствора $\left(1 \mathrm{M} \mathrm{CH}_{3} \mathrm{COONH}_{4}\right)$ в течение суток при соотношении почва - раствор 1:10.

Поровая вода исследуемых проб почв была выделена центрифугированием с дальнейшим исследованием декантата [33].

Все жидкие фракции анализировались методом масс-спектрометрии с индуктивносвязанной плазмой с использованием масс-спектрометра Agilent 7500 фирмы Agilent Technol (США) в Институте химии и химической технологии СО РАН.

\section{Результаты и обсуждение}

\section{Исследование почв}

С помощью метода последовательного фракционирования можно оценить относительную подвижность металлов и их формы связывания с почвенными компонентами $[34,35]$. Водорастворимые и обменные формы соединений принято считать «подвижными», т.е. доступными для растений, а значит, активно включающимися в круговорот веществ и наиболее опасными для экосистемы.

В табл. 1 представлены данные о содержании урана (мкг) в водорастворимой (фракция 1) и обменной (фракция 2) фракциях корневой ризосферы, сухих и естественно-влажных пробах экспериментальных почв. 
Таблица 1. Содержание урана в офракциях экспериментальных почв, мкг (\% выделенного урана)

\begin{tabular}{|c|c|c|c|c|c|c|}
\hline $\begin{array}{l}\text { Номер } \\
\text { пробы }\end{array}$ & $\begin{array}{c}\text { Вносимые } \\
\text { компоненты }\end{array}$ & Фракция & $\begin{array}{c}\text { Почва корневой } \\
\text { ризосферы }\end{array}$ & $\begin{array}{c}\text { Естественно- } \\
\text { влажная почва }\end{array}$ & Сухая почва & $\begin{array}{c}\text { Общий выход } \\
\text { урана для } \\
\text { всей почвы }\end{array}$ \\
\hline \multirow{3}{*}{1} & \multirow{3}{*}{ Контроль } & 1 & $\begin{array}{c}0,07 \pm 0,001 \\
(2 \pm 0,02)\end{array}$ & $\begin{array}{c}0,28 \pm 0,001 \\
(9 \pm 0,05)\end{array}$ & $\begin{array}{c}0,03 \pm 0,001 \\
(1 \pm 0,001)\end{array}$ & \multirow{3}{*}{$\begin{array}{l}2,89 \pm 0,20 \\
\quad(100)\end{array}$} \\
\hline & & 2 & $\begin{array}{l}0,99 \pm 0,01 \\
(34 \pm 0,03)\end{array}$ & $\begin{array}{l}0,78 \pm 0,02 \\
(26 \pm 0,04)\end{array}$ & $\begin{array}{c}0,74 \pm 0,04 \\
(24 \pm 1)\end{array}$ & \\
\hline & & $1+2$ & $\begin{array}{c}1,06 \pm 0,55 \\
(36 \pm 1)\end{array}$ & $\begin{array}{c}1,06 \pm 0,14 \\
(36 \pm 1)\end{array}$ & $\begin{array}{c}0,77 \pm 0,17 \\
(26 \pm 0,5)\end{array}$ & \\
\hline \multicolumn{7}{|c|}{ С вычетом контроля } \\
\hline \multirow{3}{*}{2} & \multirow{3}{*}{ Добавка нефти } & 1 & $\begin{array}{c}0,04 \pm 0,001 \\
(1 \pm 0,004)\end{array}$ & $\begin{array}{c}0,22 \pm 0,003 \\
(6 \pm 0,02)\end{array}$ & $\begin{array}{c}0,17 \pm 0,002 \\
(5 \pm 0,002)\end{array}$ & \multirow{3}{*}{$\begin{array}{l}3,59 \pm 0,50 \\
\quad(100)\end{array}$} \\
\hline & & 2 & $\begin{array}{c}0,42 \pm 0,01 \\
(11 \pm 0,009)\end{array}$ & $\begin{array}{c}1,86 \pm 0,01 \\
(51 \pm 1)\end{array}$ & $\begin{array}{c}0,88 \pm 0,001 \\
(24 \pm 0,03)\end{array}$ & \\
\hline & & $1+2$ & $\begin{array}{l}0,46 \pm 0,17 \\
(12 \pm 0,08)\end{array}$ & $\begin{array}{l}2,08 \pm 0,15 \\
\quad(57 \pm 1)\end{array}$ & $\begin{array}{l}1,05 \pm 0,18 \\
(29 \pm 0,02)\end{array}$ & \\
\hline \multirow{3}{*}{3} & \multirow{3}{*}{$\begin{array}{l}\text { Добавка } \\
\text { пластовой воды }\end{array}$} & 1 & $\begin{array}{c}0,10 \pm 0,001 \\
(3 \pm 0,05)\end{array}$ & $\begin{array}{c}0,66 \pm 0,04 \\
(18 \pm 0,3)\end{array}$ & $\begin{array}{c}0,03 \pm 0,001 \\
(1 \pm 0,02)\end{array}$ & \multirow{3}{*}{$\begin{array}{l}3,69 \pm 0,45 \\
\quad(100)\end{array}$} \\
\hline & & 2 & $\begin{array}{c}0,67 \pm 0,4 \\
(45 \pm 2)\end{array}$ & $\begin{array}{c}0,95 \pm 0,003 \\
(26 \pm 1)\end{array}$ & $\begin{array}{c}0,28 \pm 0,005 \\
(7 \pm 0,02)\end{array}$ & \\
\hline & & $1+2$ & $\begin{array}{c}1,77 \pm 0,17 \\
(48 \pm 1)\end{array}$ & $\begin{array}{l}1,61 \pm 0,31 \\
(44 \pm 0,06)\end{array}$ & $\begin{array}{c}0,31 \pm 0,03 \\
(8 \pm 0,04)\end{array}$ & \\
\hline \multirow{3}{*}{4} & \multirow{3}{*}{$\begin{array}{l}\text { Добавка урана и } \\
\text { нефти }\end{array}$} & 1 & $\begin{array}{l}0,01 \pm 0,000 \\
(0,1 \pm 0,000)\end{array}$ & $\begin{array}{l}0,06 \pm 0,001 \\
(0,8 \pm 0,001)\end{array}$ & $\begin{array}{l}0,05 \pm 0,001 \\
(0,6 \pm 0,001)\end{array}$ & \multirow{3}{*}{$\begin{array}{l}8,01 \pm 0,30 \\
\quad(100)\end{array}$} \\
\hline & & 2 & $\begin{array}{c}2,88 \pm 0,04 \\
(36 \pm 0,9)\end{array}$ & $\begin{array}{l}4,16 \pm 0,003 \\
(52 \pm 1)\end{array}$ & $\begin{array}{c}0,85 \pm 0,01 \\
(10 \pm 1)\end{array}$ & \\
\hline & & $1+2$ & $\begin{array}{l}2,89 \pm 1,04 \\
(36 \pm 0,07)\end{array}$ & $\begin{array}{c}4,22 \pm 0,71 \\
(53 \pm 0,8)\end{array}$ & $\begin{array}{l}0,90 \pm 0,19 \\
(11 \pm 0,02)\end{array}$ & \\
\hline
\end{tabular}

Для начала отметим, что природный уран в небольших количествах присутствует во всех природных компонентах: почве, воде, живых организмах и т.д. В этом нет ничего удивительного, ведь этот элемент включается в различные химические процессы, а для растений, например, он необходим для нормального развития [27]. Однако в высоких концентрациях уран проявляет обратный - негативный - эффект, о чем уже упоминалось.

Данные табл. 1 показывают, что общее содержание урана для всех фракций контрольной пробы составляет 2,89 мкг. Во фракциях почвы корневой ризосферы и естественно-влажной почвы содержание урана примерно одинаково (1,06 мкг и по 36 \% от общего выхода урана). В сухой почве содержание урана во фракциях 0,77 мкг ( $26 \%$ от общего выхода урана в контрольной пробе). Содержание урана в экспериментальных пробах (куда была внесена нефть, пластовая вода и уран) представлено в табл. 1 с вычетом контрольной пробы.

Для всех экспериментальных проб характерен наибольший выход урана с обменной фракцией. Максимальный выход урана с обменной фракцией приходится на пробу естественновлажной почвы с добавлением нефти и урана $(4,16$ мкг и $52 \%$ от общего выхода урана в этой пробе), минимальный - на пробу сухой почвы с добавлением пластовой воды (0,28 мкг и 7 \% от общего выхода урана в этой пробе). 
Суммарное содержание урана для фракций почвы корневой ризосферы максимальное значение имеет в пробе с добавлением нефти и урана (2,89 мкг и 36 \% от общего выхода урана в этой пробе), минимальное - в пробе с добавлением нефти (0,46 мкг и 12 \% от общего выхода урана в этой пробе).

Суммарное содержание урана для фракций естественно-влажной почвы максимальное значение имеет в пробе с добавлением нефти и урана (4,22 мкг и 53 \% от общего выхода урана в этой пробе), минимальное - в пробе с добавлением пластовой воды (1,61 мкг и 44 \% от общего выхода урана в этой пробе).

Суммарное содержание урана для фракций сухой почвы максимальное значение имеет в пробе с добавлением нефти (1,05 мкг и 29 \% от общего выхода урана в этой пробе), минимальное - в пробе с добавлением пластовой воды $(0,31$ мкг и $8 \%$ от общего выхода урана в этой пробе).

Стоит отметить, что посредством фракционирования из естественно-влажной почвы извлекается урана больше, чем из сухой во всех пробах. Обнаруженная разница подтверждается проведенными ранее исследованиями по сопоставлению и сравнению фракционирования таких почв $[34,36,37]$. Это вызвано, прежде всего, изменением структуры почвы при высушивании. Следовательно, при выявлении доли подвижной, а значит, и биодоступной доли металлов, в том числе и радионуклидов, предпочтение должно отдаваться именно естественно-влажным почвам.

Для пробы с внесенной нефтью и ураном нам известно, что содержание внесенного в пробу урана составляет около 480 мкг (т.к. это без учета природного урана в нефти). Так, выход урана с почвенными экстрактами составил 8,01 мкг (около 2 \% от внесенного урана). Определенная часть урана перешла в растения. Еще часть урана могла выйти с дренажной водой [38]. Так как почва является глинистой, можно предположить, что остальная (около 96 \%) часть урана осталась в почве и связалась с глинистыми минералами.

Способность почв удерживать радионуклид оценена по величине коэффициента межфазного распределения $\mathrm{K}_{\mathrm{D}}$ - отношение между удельными активностями твердой фазы и порового раствора почвы в состоянии межфазного равновесия. Результаты расчетов приведены в табл. 2.

Представленные в табл. 2 результаты показывают, что внесение в систему нефти способствует перераспределению урана, прочно зафиксированного во фрагментах почвы, в более растворимые формы.

Поглощение радионуклида твердой фазой в системе «почва - уран - нефть» с $\mathrm{pH}<7,5$ обусловлено их легкой гидролизуемостью в этой области $\mathrm{pH}[39,40]$, в результате чего образуются смеси из полимерных гидроксо- и аквагидроксокомплексов макрокомпонентов ( $\mathrm{Si}, \mathrm{Fe}, \mathrm{Al}$ и др.) и внесенного урана. Такие соединения могут образовывать золь, способную затем превращаться в гель, который, в свою очередь, захватывается поверхностью почв. Эти процессы могут быть описаны следующим фазовым превращением:

$$
\left(\mathrm{M}_{2}{ }^{\prime} \mathrm{O}\right)_{x}\left(\mathrm{M}^{\prime \prime} \mathrm{O}\right)_{y}\left(\mathrm{SiO}_{2}\right)_{z}\left(\mathrm{Al}_{2} \mathrm{O}_{3}\right)_{k}\left(\mathrm{Fe}_{2} \mathrm{O}_{3}\right)_{m},
$$

где $\mathrm{M}^{\prime}=\mathrm{K}^{+}, \mathrm{Na}^{+}, \mathrm{M}^{\prime \prime}=\mathrm{Mg}^{2+}, \mathrm{Ca}^{2+}$.

$$
\text { Гель (s) } \leftrightarrow \text { Золь (aq) }
$$


Таблица 2. Коэффициенты распределения урана между содержанием в поровой воде и твердом остатке почве в естественно-влажном состоянии

\begin{tabular}{|c|c|c|}
\hline Номер & Система & К \\
\hline 1 & Почва - контроль & 17000 \\
\hline 2 & Почва + нефть & 10100 \\
\hline 3 & Почва + пластовая вода & 11000 \\
\hline 4 & Почва + уран + нефть & 9850 \\
\hline
\end{tabular}

С точки зрения конкурирующего процесса поглощения урана твердой фазой одновременно протекает процесс, связанный с растворением осажденных ранее соединений в виде устойчивых карбонатных комплексов. Например, образование карбонатных комплексов с внесенным ураном [41].

В зависимости от условий проведения экспериментов конкурирующий процесс, связанный с образованием растворимых карбонатных комплексов, а также образование коллоидных и псевдоколлоидных частиц в растворе могут уменьшать коэффициенты распределения радионуклидов, способствуя образованию их миграционноспособных форм.

\section{Исследования растений}

В табл. 3 представлены результаты содержания урана в экстракте (ацетат-аммонийной вытяжке) корневой и наземной частей экспериментальных растений (подвижные формы), а также содержание урана в корневой и наземной частях биомассы растения (с пересчетом на 1 г).

Как показано в табл. 3, доля накопленного урана в наземных и корневых системах в контрольной системе практически одинакова и составляет $\sim 50 \%$. При внешнем воздействии, т.е. при внесении нефти, пластовой воды и смеси уран-нефть, наблюдается изменение соотношений между содержанием U-238 в корневой и наземной частях растений. Так, при внесении нефти и пластовой воды содержание урана в корневой части значительно выше, чем в наземной части. И при этом внесенная пластовая вода увеличивает содержание урана в корневой части до 89 \%, что в 8 раз выше содержания в наземной части рассматриваемой экспериментальной системы. В системе с внесенной нефтью получена разница между корневой и наземной частями менее чем в 2 раза (34 и 66 \% для корневой и наземной частей соответственно). Однако в этой системе наблюдается большее концентрирование растениями урана, имеющегося в исходной пробе почвы - около 20 мкг/сухой почвы, что незначительно отличается от содержания урана, накопленного растениями в системе с внесенными ураном и нефтью. Тем самым можно предположить, что органические вещества, присутствующие в нефти, способствуют образованию биодоступных для корневой системы форм урана, что, следовательно, приводит к большему накоплению U-238 в корневой системе и далее во всей биомассе растения.

При внесении и урана, и нефти в экспериментальную систему наблюдалось увеличение доли U-238 в наземной части растения ( $65 \%$ ), что заметно выше по сравнению с содержанием в корневой системе ( $35 \%)$.

В системе, в которую была внесена пластовая вода, растения завяли через неделю после внесенного раствора, тогда как в других исследуемых системах растения развивались.

$$
-36-
$$


Таблица 3. Содержание урана в частях (корневая система и наземная часть) экспериментальных растений и ацетат-аммонийных экстрактах, мкг/г сухого веса (\% выделенного урана)

\begin{tabular}{|c|c|c|c|c|}
\hline \multirow{2}{*}{$\begin{array}{c}\text { Вносимые } \\
\text { компоненты }\end{array}$} & \multirow[b]{2}{*}{ Часть растения } & \multicolumn{3}{|c|}{ Содержание урана, мкг/г сухого веса (доля от общего \%) } \\
\hline & & В экстракте & $\begin{array}{c}\text { По частям } \\
\text { растений }\end{array}$ & Общее содержание \\
\hline \multirow{2}{*}{ - (Контроль) } & Наземная часть & $\begin{array}{c}0,070 \pm 0,003 \\
(4,4 \pm 0,2)\end{array}$ & $\begin{array}{c}0,78 \pm 0,04 \\
(49 \pm 2)\end{array}$ & \multirow[t]{2}{*}{$\begin{array}{l}1,59 \pm 0,07 \\
\quad(100)\end{array}$} \\
\hline & Корневая система & $\begin{array}{c}0,040 \pm 0,002 \\
(2,5 \pm 0,1)\end{array}$ & $\begin{array}{l}0,81 \pm 0,04 \\
(51 \pm 2)\end{array}$ & \\
\hline \multirow{2}{*}{ Добавка нефти } & Наземная часть & $\begin{array}{c}0,190 \pm 0,009 \\
(0,90 \pm 0,04)\end{array}$ & $\begin{array}{r}6,7 \pm 0,3 \\
(34 \pm 1)\end{array}$ & \multirow[t]{2}{*}{$\begin{array}{c}19,6 \pm 0,9 \\
(100)\end{array}$} \\
\hline & Корневая система & $\begin{array}{c}0,120 \pm 0,006 \\
(0,60 \pm 0,03)\end{array}$ & $\begin{array}{c}12,9 \pm 0,6 \\
(66 \pm 3)\end{array}$ & \\
\hline \multirow{2}{*}{$\begin{array}{c}\text { Добавка пластовой } \\
\text { воды }\end{array}$} & Наземная часть & $\begin{array}{r}0,150 \pm 0,008 \\
(1,30 \pm 0,06)\end{array}$ & $\begin{array}{l}1,17 \pm 0,06 \\
(10,5 \pm 0,5)\end{array}$ & \multirow[t]{2}{*}{$\begin{array}{l}11,1 \pm 0,6 \\
(100)\end{array}$} \\
\hline & Корневая система & $\begin{array}{c}0,30 \pm 0,02 \\
(2,7 \pm 0,1) \\
\end{array}$ & $\begin{array}{l}9,9 \pm 0,5 \\
(89 \pm 4)\end{array}$ & \\
\hline \multirow{2}{*}{$\begin{array}{c}\text { Добавка урана и } \\
\text { нефти }\end{array}$} & Наземная часть & $\begin{array}{c}0,24 \pm 0,01 \\
(0,90 \pm 0,05)\end{array}$ & $\begin{array}{c}17,1 \pm 0,8 \\
(65 \pm 3)\end{array}$ & \multirow[t]{2}{*}{$\begin{array}{l}27 \pm 1 \\
(100)\end{array}$} \\
\hline & Корневая система & $\begin{array}{c}0,38 \pm 0,02 \\
(1,40 \pm 0,07)\end{array}$ & $\begin{array}{c}9,4 \pm 0,5 \\
(35 \pm 1)\end{array}$ & \\
\hline
\end{tabular}

Таким образом, проанализировав всю полученную информацию, мы сделали следующие выводы. Около 96 \% урана связывается с компонентами почвы (органическим веществом, глинистыми минералами) после внесения. При этом около 2 \% урана извлекается из почвы вместе с подвижными фракциями и накапливается в растении. Максимальный выход урана происходит с ацетатно-аммонийной вытяжкой (обменная фракция). Выход урана посредством последовательного фракционирования зависит от состояния почвы: из естественно-влажных почв извлекается урана больше, чем из сухих. Содержание урана в корневой и наземной частях растений в системах с добавлением нефти и пластовой воды много выше, чем в контрольной системе (от 1,17 до 6,73 мкг по сравнению с 0,78 в наземной части растений и от 9,92 до 12,87 по сравнению с 0,81 мкг в корневой части растений). Возможно, нефть, внесенная в систему, способствует перераспределению урана из прочно связанных форм в почве в растворимые формы. При внесении урана вместе с нефтью содержание радионуклида в наземной части заметно отличается от содержания в корневой части растения (17,1 в наземной части и 9,43 мкг в корневой части растений). Растения во время полива экспериментальными растворами находились в вегетационном периоде, и мы можем предположить, что внесенный раствор урана сыграл роль удобрения. Доказательством этому явилось то, что в пробах с внесенным ураном было отмечено цветение растений к концу эксперимента. Возможно, именно с этим и связано более высокое, чем в корневой части, содержание урана в наземной части растений.

Работа выполнена при частичной финансовой поддержке Российского фонда фундаментальных исследований (РФФИ 16-05-00205). 


\section{Список литературы}

1. Абдулаева А.С. Радиоактивность горных пород, почв, природных вод Дагестана и обусловленные ими эффективные дозы. Юг России: экология, развитие 2012. № 3. С. 89-106. [Abdullayeva A.S. Radioactivity of rocks, soils, natural waters and Daghestan due to their effective doses. South of Russia: the environment, the development 2012. № 3, P. 89-106. (In Russ.)]

2. Гашев С.Н., Моисеенко Т.И. Тяжелые металлы и радионуклиды как фактор риска для биоты в экологическом мониторинге Тюменской области. Вестник ТюмГУ 2012. № 12. С. 2636. [Gashev S.N., Moiseenko T.I. Heavy metals and radionuclides as a risk factor for biota in the environmental monitoring of the Tyumen region. Vestnik of Tyumen State University 2012, № 12, P. 26-36. (In Russ.)]

3. Глухов Г.Г., Зукау Ю.В., Нестерова В.В., Чикова И.В. Радиационный контроль в современных процессах нефтедобычи. Вестник науки Сибири 2012, № 2, C. 16-21. [Gluhov G.G., Zukau Y.V., Nesterov V.V., Chikova I.V. Radiation monitoring in modern oil production processes. Journal of Science of Siberia 2012. № 2. P. 16-21. (In Russ.)]

4. Губайдуллин М.Г., Иванов Р.С. Интегральная оценка воздействия нефтей на окружающую среду с учетом их компонентного состава. Вестник Поморского университета 2007. № 1(11). C. 5-12. [Gubaidullin M.G., Ivanov R.S. Integral assessment of the impact of oil on the environment with regard to their component composition. Vestnik Pomor University 2007, № 1 (11), P. 5-12. (In Russ.)]

5. Гумерова Р.Х., Батрутдинов О.Р., Селивановская С.Ю. Влияние радиоактивных отходов нефтедобывающего производства на почвенные организмы и растения. Труды Всероссийской научной конференции с международным участием. Казань, 2009. C. 65-68. [Gumerova A.D., Batrutdinov O.R., Selivanovskaya S.Y. Impact of radioactive waste oil production on soil organisms and plants. Proceedings of the All-Russian Scientific Conference with international participation 2009, P. 65-68. (In Russ.)]

6. Мустафин С.К. Пластовые воды месторождений углеводородов: экомониторинг, защита, перспективы освоения. Нефть и газ Западной Сибири: материалы Международной научнотехнической конференции. Тюмень, 2013. C. 17-20. [Mustafin S.K. Formation water hydrocarbon fields: environmental monitoring, protection, development prospects. Oil and gas in Western Siberia: Materials of the International scientific-technical conference 2013, P. 17-20. (In Russ.)]

7. Swann C., Matthews J., Ericksen R., Kuszmaul J. Evaluations of radionuclides of uranium, thorium, and radium associated with produced fluids, precipitates, and sludges from oil, gas, and oilfield brine injections wells in Mississippi. U.S. Department of Energy 2004, P. 1-23.

8. Termizi Ramli A., Wahab A., Hussein M.A., Khalik Wood A. Environmental 238U and 232Th concentration measurements in an area of high level natural background radiation at Palong, Johor, Malaysia. Journal of Environmental Radioactivity 2005. Vol. 80, P. 287-304.

9. Rowan E.L., Engle M.A., Kirby C.S., Kraemer T.F. Radium Content of Oil- and Gas-Field Produced Waters in the Northern Appalachian Basin (USA): Summary and Discussion of Data. Scientific Investigations Report, 2011. 31 p.

10. Григориади А.С., Амирова А.Р., Лопатин Н.В. Оценка эффективности посевов различных фиторемедиантов для восстановления нефтезагрязненной серой лесной почвы. Известия Самарского научного центра РАН 2013. № 3. C. 1266-1268. [Grigoriadi A.S., Amirova A.R., 
Lopatin N.V. Evaluating the effectiveness of various crops fitoremediantov to recover oily gray forest soils. Proceedings of the Russian Academy of Sciences, Samara Scientific Center 2013. № 3. P. 12661268. (In Russ.)]

11. Гриценко П.П. Экологические, социальные и эколого-экономические аспекты нефтедобычи в Ханты-Мансийском автономном округе. Актуальные проблемы развития нефтегазового комплекса Западной Сибири: материалы региональной научно-практической конференции, посвященной 25-летию филиала ТюмГНГУ в г. Нефтеюганске 2013. C.132-151. [Gritsenko P.P. Environmental, social, ecological and economic aspects of oil production in the Khanty-Mansi Autonomous District. Actual problems of the development of oil and gas complex of Western Siberia: Materials of regional scientific-practical conference dedicated to the 25th anniversary of the branch Nefteyugansk TSOGU 2013. P.132-151. (In Russ.)]

12. Дорожукова С.Л., Янин Е.П. Экологические проблемы нефтегазодобывающих территорий Тюменской области. М.: ИМГРЭ, 2004. 56 с. [Dorozhukova S.L., Yanin E.P. Environmental problems of oil and gas producing areas of the Tyumen region. Moscow: IMGRE, 2004. 56 p. (In Russ.)]

13. Бураева Е.А., Малышевский В.С., Вардуни Т.В., Шиманская Е.И. Содержание и распределение естественных радионуклидов в различных типах почвы Ростовской области. Современные проблемы науки и образования. 2013. № 4. C. 1-9. [Buraeva E.A., Malyshevsky V.S., Varduni T.V., Shimanskaya E.I. The content and distribution of natural radionuclides in different types of soils of the Rostov region. Modern problems of science and education 2013. № 4, P. 1-9. (In Russ.)]

14. Денисова Т.В. Радиоэкология: учебно-методическое пособие для студентов вузов. Часть 1. Ростов-на-Дону: УПЛ РГУ, 2006. 39 с. [Denisova T.V. Radioecology: Part 1. Study guide for university students. Rostov-on-Don: UPL RSU, 2006. 39 p. (In Russ.)]

15. Егорова И.А., Пузанов А.В., Балыкин С.Н. Естественные радионуклиды (238U, 232Th, 40K) в высокогорных почвах Северо-Западного Алтая. Мир науки, культуры, образования. 2007. № 4. C. 16-19. [Egorova I.A., Puzanov A.V., Blokhin S.N. Natural radionuclides (238U, 232Th, 40K) in the highland soils northwestern Altai. World of Science, Culture, Education, 2007. № 4, P. 16-19. (In Russ.)]

16. Кочиш И.И., Содбоев Ц.Ц., Щукин М.В., Давыденко Н.М. Особенности вертикального распределения радионуклидов в почвах луговых агроценозов Шатурского района Московской области. Ветеринария, зоотехния и биотехнология. 2014. № 6. С. 36-40. [Kocsis I.I., Sodboev TS.TS., Shchukin M.V., Davydenko N.M. Features of the vertical distribution of radionuclides in soil meadow agrotcenozov Shatura district, Moscow region. Veterinary science, animal science and biotechnology 2014. № 6, Р. 36-40. (In Russ.)]

17. Павлоцкая Ф.И. Миграция радиоактивных продуктов глобальных выпадений в почвах. М: Атомиздат, 1974. 216 с. [Pavlotskaya F.I. The migration of the radioactive products of global fallout in soils. Moscow: Atomizdat, 1974. 216 p. (In Russ.)]

18. Рачкова Н.Г., Шуктомова И.И., Таскаев А.И. Состояние в почвах естественных радионуклидов урана, радия и тория (обзор). Почвоведение 2010. № 6. C. 698-705. [Rachkova N.G., Shuktomova I.I., Taskaev A.I. Status of natural uranium in soil radionuclide, radium, and thorium (review). Soil 2010. № 6. P. 698-705. (In Russ.)] 
19. Сковородникова Н.А. Распределение 137Cs и естественных радионуклидов по профилю дерново-подзолистых почв различных экосистем. Вестник Брянского государственного университета. 2010. № 4. С. 225-227. [Skovorodnikova N.A. Distribution of 137Cs and natural radionuclides in the profile of sod-podzolic soils of different ecosystems. Herald Bryansk State University 2010. № 4. P. 225-227. (In Russ.)]

20. Blanco Rodriguez P., Tome F. Vera, Lozano J. C. Vertical distribution of natural radionuclides in soils. EPJ Web of Conferences 2012. № 24. P. 1-5.

21. Ковда В.А. Биогеохимия почвенного покрова. Москва: Наука, 1985. 263 с. [Kovda V.A. Biogeochemistry of soil. Moscow: Science, 1985. 263 p. (In Russ.)]

22. Арбузов С.И., Рихванов Л.П. Геохимия радиоактивных элементов: учебное пособие. Томск: ТПУ, 2011. 300 c. [Arbuzov S.I., Rikhvanov L.P. Geochemistry of radioactive elements: a tutorial. Tomsk: TPU, 2011. 300 p. (In Russ.)]

23. Бурачевская М.В. Фракционный состав соединений тяжелых металлов в черноземах обыкновенных Нижнего Дона: дис. ... канд. биол. наук 2015. С. 23-49. [Burachevskaya M.V. Fractional composition of heavy metals in chernozem ordinary the lower Don: Dis. cand. biol. sciences 2015. P. 23-49. (In Russ.)]

24. Blanco Rodriguez P., F. Vera Tome, M. Perez Fernandez, J.C. Lozano. Linearity assumption in soil-to-plant transfer factors of natural uranium and radium in Helianthus annuus L. Science of the total environment. 2006.Vol. 361, P.1-7.

25. ГОСТ 17.4.3.01-83. Охрана природы. Почвы. Общие требования к отбору проб. М.: Издво стандартов, 2004. 3 с. [GOST 17.4.3.01-83. Protection of Nature. Soils. General requirements for sampling. Moscow: Izdatelstvovo Standartov, 2004. 3 p. (In Russ.)]

26. ГОСТ 17.4.4.02-84. Охрана природы. Почвы. Методы отбора и подготовки проб для химического, бактериологического, гельминтологического анализа. М.: Издательствово стандартов, 1985. 14 c. [GOST 17.4.4.02-84. Protection of Nature. Soils. Methods of sampling and sample preparation for chemical, bacteriological, helminthological analysis. Moscow: Izdatelstvovo Standartov 1985. 14 p. (In Russ.)]

27. Kabata-Pendias A., Pendias H. Trace elements in the biological Environment. Wyd. Geol. Warsaw 1979. $300 \mathrm{p}$.

28. Toutova T.N. Morphometric investigation of plants Tagetes erecta 1. of different varieties. Biology \& Earth Sciences. 2015. Issue 2. P. 109-114.

29. Киреева Н.А., Григориади А.С. Оценка реакции растений-фиторемедиантов, произрастающих на территории нефтешламового амбара, по эколого-физиологическим показателям. Известия Оренбургского государственного аграрного университета. 2012. № 6(38). С. 209211. [Kireeva N.A., Grigoriadi A.S. Evaluation-fitoremediantov plant response, oil sludge growing in the barn, on the ecological and physiological indicators. Proceedings of the Orenburg State Agrarian University 2012. № 6 (38), P. 209-211. (In Russ.)]

30. Hung-Yu Lai. Heavy Metals Contaminated Soils and Phytoremediation Strategies in Taiwan. Soil Contamination 2011. P.107-127.

31. Монголина Т.А., Барановская Н.В., Соктоев Б.Р. Элементный состав солевых отложений питьевых вод Томской области. Известия Томского политехнического университета. 2011. № 1 (319), C. 204-211. [Mongolina T.A., Baranovskaya N.V., Soktoev B.R. Elemental composition of 
the salt deposits of drinking water of the Tomsk region. Bulletin of the Tomsk Polytechnic University 2011. № 1 (319), P.204-211. (In Russ.)]

32. Douglas A Skoog, Donald M West, F James Holler. Fundamentals of Analytical Chemistry, Sixth Edition. Sanders Colege Pablishing: New York, 1992. 976 p.

33. Другов Ю.С., Родин А.А. Пробоподготовка в экологическом анализе. М.: БИНОМ. Лаборатория знаний, 2009. 855 с. [Drugov Y.S., Rodin A.A. Sample preparation in environmental analysis. Moscow: Binom. Knowledge Laboratory, 2009. 855 p. (In Russ.)]

34. Бондарева Л.Г. Миграция техногенных радионуклидов в водном потоке р. Енисей. Радиохимия. 2012. № 1. C. 91-96. [Bondareva L.G. The migration of radionuclides in the water flow of the Yenisei River. Radiochemistry 2012, № 1. P. 91-96. (In Russ.)]

35. Bondareva L., Mogilnaya O., Vlasova I. Subcellular localization of $241 \mathrm{Am}$ in structural components of submerged macrophyte of the River Yenisei Elodea Canadensis. International Aquatic Research. 2012. № 4. Р. 13-28.

36. Бондарева Л.Г., Калякина О.П., Маркова Ю.Ю. Изучение состава гуматно-фульватного комплекса донных отложений реки Енисей в ближней зоне влияния горно-химического комбината Росатома. Журнал СФУ. Химия. 2009. Т. 2(2). С. 178-186. [Bondareva L.G., Kalyakina O.P., Markova Y.Y. Studying the composition of humate-fulvate complex of bottom sediments of the Yenisei River in the near zone of influence of mining and chemical plant Rosatom. SFU Journal. Chemistry 2009. Vol. 2(2), P. 178-186. (In Russ.)]

37. Бондарева Л.Г., Болсуновский А.Я., Трапезников А.В., Дегерменджи А.Г. Использование новой методики концентрирования трансурановых элементов в пробах воды р. Енисей. ДАН. 2008. Т. 423(4). С. 479-482. [Bondareva L.G., Bolsunovsky A.Y., Trapeznikov A.V., Degermendzhi A.G. Using the new technique concentrating of transuranic elements in the Yenisei River water samples. DAN 2008. Vol. 423(4), P. 479-482. (In Russ.)]

38. Миронова А.С., Краплякова Н.С. Изучение особенностей накопления урана в почве: модельные эксперименты. Молодая нефть: сборник статей Всероссийской молодежной научнотехнической конференции нефтегазовой отрасли. Красноярск: СФУ, 2015. С. 113-117. [Mironova A.S., Kraplyakova N.S. The study of accumulation of uranium in soil: modeling experiments. Young Oil: a collection of articles all-Russian youth scientific and technical conference of the oil and gas industry. Krasnoyarsk: Siberian Federal University 2015, P. 113-117. (In Russ.)]

39. Schüßler W., Artinger R., Kienzler B. Conceptual Modeling of the Humic Colloid-Borne Americium (III) Migration by a Kinetic Approach. Environmental Science and Technology 2000. Vol. 34, P. 2608-2611.

40. Sillen L.G. Stability constants of metal-ion complexes. The Chem. Soc. Burlington House, London. 1971. Suppl. 1, N 25, P. 865.

41. Katz J.J., Seaborg G.T., Morss L.R. The Chemistry of the Actinide Elements. Vol.1. Springer Netherlands, 1986.990 p. 